\title{
First detection of Candidatus Rickettsia barbariae in the flea Vermipsylla alakurt from north-western China
}

\author{
Shan-Shan Zhao ${ }^{1 \dagger}$, Hong-Yu Li ${ }^{1 \dagger}$, Xiao-Ping Yin², Zhi-Qiang Liư ${ }^{3}$, Chuang-Fu Chen ${ }^{3}$ and Yuan-Zhi Wang ${ }^{1 *}$
}

\begin{abstract}
Background: Vermipsylla is a genus of the family Vermipsyllidae within the order Siphonaptera of fleas. Vermipsylla alakurt is mainly distributed in alpine pastoral areas of Kazakhstan, Mongolia, China and Nepal, and infests sheep, yaks and horses, causing irritation, poor condition, anaemia and even death. However, to date, no rickettsial agents have been reported in $V$. alakurt.

Findings: A total of 133 fleas were collected directly from the tails of three sheep flocks $(n=335)$ in Minfeng County, Xinjiang Uygur Autonomous Region, north-western China. Of these, 55 fleas were identified by morphological examination and molecular analysis of four loci (the ribosomal 185 and 285 rDNA genes and the mitochondrial genes cytochrome c oxidase subunit II and elongation factor 1-alpha). Eight Rickettsia-specific gene fragments originated from seven genes: the 17-kilodalton antigen gene (17-kDa), citrate synthase gene ( $g / t A), 16 S$ rRNA gene (rrs), outer membrane protein A gene (ompA), surface cell antigen 1 gene (sca1), PS120 protein gene (gene D), and outer membrane protein B gene (ompB, two fragments), were used to identify the species of Rickettsia in 53 fleas. The amplified products were sequenced and included in a phylogenetic analysis to verify the taxonomic identification of the rickettsial agents. Based on morphological and molecular evidence, the flea was identified as Vermipsylla alakurt. Nine samples were positive $(16.98 \%, 9 / 53)$ for Rickettsia spp. The phylogenetic tree revealed that the rickettsial agents found in V. alakurt cluster with Candidatus Rickettsia barbariae.
\end{abstract}

Conclusions: Our study suggests that: (i) V. alakurt may serve as a carrier for Candidatus R. barbariae; and (ii) Candidatus R. barbariae, previously reported in Israel, is the eighth newly discovered validated Rickettsia species in China. This finding extends our knowledge of the distribution of Candidatus R. barbariae and the profile of carriers, which not only comprise ticks but also fleas.

Keywords: Candidatus Rickettsia barbariae, Vermipsylla alakurt, North-western China

\section{Findings}

\section{Background}

Fleas (Insecta: Siphonaptera) are small, laterally flattened, wingless, and highly specialised insects [1]. About 2575 species belonging to 16 families and 246 genera have been described, but only a minority is closely associated with humans and other animals $[1,2]$. Vermipsylla is a genus of the family Vermipsyllidae within the Siphonaptera [3-5]. At least eight species, i.e.

\footnotetext{
* Correspondence: wangyuanzhi621@126.com

${ }^{\dagger}$ Equal contributors

'School of Medicine, Shihezi University, Shihezi, Xinjiang Uygur Autonomous Region 832000, China

Full list of author information is available at the end of the article
}

Vermipsylla alakurt (Kazakhstan, Mongolia, China), V. asymmetrica (China), V. ibexa (China), V. minuta (China), V. parallela (China), V. perplexa (China, Nepal), $V$. quilianensis (China) and $V$. yeae (China), have been described [6, 7]. Vermipsylla alakurt was first identified in China in 1965, in the southern region of Xinjiang Uygur Autonomous Region (XUAR, north-western China) [6]. During December to January, the adult flea is mainly endemic in alpine pastoral areas in XUAR and Qinghai Province (northern China). It infests sheep, yaks and horses, and causes irritation, poor condition, anemia and even death [8-10].

Fleas are mainly blood vessel feeders [11]. The effect of concern of this dietary preference is that fleas 
themselves are hosts to pathogens, and thus provide a natural avenue for pathogen dispersal [12, 13]. Members of the Rickettsiaceae, such as Rickettsia typhi and R. felis, are well known as flea-borne pathogens [14]. To the best of our knowledge, little is known about rickettsial agents in $V$. alakurt. In the present study, a molecular investigation was carried out to identify Rickettsia spp. in $V$. alakurt.

\section{Methods}

\section{Collection of fleas and morphological identification}

In December 2013, fleas (133 in total) were collected directly from the tails of three sheep flocks $(n=335)$ at Yeyike Town (3300 $\mathrm{m}$ above sea level; 36 $74.93 \mathrm{~N}, 83^{\circ}$ 0026 E), Minfeng County, near the Taklimakan Desert, in the southern region of XUAR. The fleas were first identified morphologically. According to an agreement between the Veterinary Research Institute, Xinjiang Academy of Animal Sciences (XAAS) and the School of Medicine, Shihezi University (SU), the fleas were divided into three samples on the basis of their number of morphological differences at the species level. One sample $(n=78)$, belonging to XAAS, was used for full-length mitochondrion sequencing (these data have not been published). The second sample $(n=53)$, belonging to $\mathrm{SU}$, was used for the molecular study of fleas and the detection of flea-borne pathogens. The last sample $(n=2$, a male and a female) was for morphological identification by the two cooperating units $[6,15]$.

\section{Molecular studies on fleas}

Total genomic DNA of 53 fleas was extracted from individual specimens using the TIANamp Genomic DNA Kit (TIANGEN, Beijing, China). The DNA of six randomly selected fleas was employed for multi-locus sequence analysis using four genes [18S ribosomal DNA (18S rDNA), $28 \mathrm{~S}$ ribosomal DNA (28S rDNA), cytochrome $c$ oxidase subunit II (COII) and elongation 1alpha $(E F-1 a)]$ to examine the phylogenetic relationships within the Siphonaptera. The primers in this study were shown in Table 1. The PCR cycling condition consisted of a pre-PCR step of $95{ }^{\circ} \mathrm{C}$ for $5 \mathrm{~min}$, followed by $35 \mathrm{cy}$ cles of $95{ }^{\circ} \mathrm{C}$ for $40 \mathrm{~s}$, annealing for $50 \mathrm{~s}$ at $59.9^{\circ} \mathrm{C}$ for amplifying $18 S r D N A$ and $28 S$ rDNA, $52.6{ }^{\circ} \mathrm{C}$ for $E F-1 a$ gene, and an extension of $72{ }^{\circ} \mathrm{C}$ for $1 \mathrm{~min}$, with a final extension of $72{ }^{\circ} \mathrm{C}$ for $10 \mathrm{~min}$. The PCR products were purified using the TIANgel Midi Purification Kit (TIANGEN) and sequenced by Sangon Biotech Co., Ltd (Shanghai, China).

\section{Detection of rickettsial agents and sequence analysis}

For genetic detection of Rickettsia spp., six PCR targets were assessed within each sample to determine the presence of Rickettsiae: a 434 bp product of the gene
Table 1 List of the primers used in the study

\begin{tabular}{llll}
\hline Gene & Primer & Sequence $\left(5^{\prime}\right.$-3') & Reference \\
\hline 18S rDNA & 18Sai & CCTGAGAAACGGCTACCACATC & {$[26]$} \\
& 18S7R & GCATCACAGACCTGTTATTGC & {$[26]$} \\
28S rDNA & 28SrD3.2a & AGTACGTGAAACCGTTCASGGGT & {$[26]$} \\
& 28SrD5b & CCACAGCGCCAGTTCTGCTTAC & {$[26]$} \\
COIl & A-tLEU & ATGGCAGATTAGTGCAATGG & {$[27]$} \\
& B-tLYS & GTTAAGAGACCAGTACTTG & {$[27]$} \\
EF-1a & EF-1a-F & GGACACAGAGATTCATCAAGAACA & This study \\
& EF-1a-R & GCAATGTGRGCHGTGTGGCA & This study \\
ompB & ompB-F & ATTTACAAGCAGGTGGTG & This study \\
& ompB-R & GCAGTGTTACCGGGATTG & This study \\
geneD & geneD-F & CGGTAACCTAGATACAAGTGA & This study \\
& geneD-R & TATAAGCTATTGCGTCATCTC & This study \\
\hline
\end{tabular}

encoding the 17 kilodalton antigen (17-kDa), $1332 \mathrm{bp}$ of 16S rRNA (rrs), 1060 bp of citrate synthase ( $g l t A)$, 488 bp of cell surface antigen 1 (sca1), 491 bp of outer membrane protein A (ompA), and 812 bp of $о m p B$, according to a previous description [16]. To confirm further the presence of rickettsial DNA in $V$. alakurt, two new pairs of primers were designed, based on another region of ompB (526 bp) and the PS120-proteinencoding gene (gene $D$; $920 \mathrm{bp}$ ) fragment sequences (accession no. GU353186 and EU272188) (see Table 1). PCR conditions consisted of a pre-PCR step of $95{ }^{\circ} \mathrm{C}$ for $5 \mathrm{~min}$, followed by 35 cycles of $95{ }^{\circ} \mathrm{C}$ for $40 \mathrm{~s}$, annealing for $30 \mathrm{~s}$ at $55^{\circ} \mathrm{C}$ for amplifying ompB and gene $D$, and an extension of $72{ }^{\circ} \mathrm{C}$ for $1 \mathrm{~min}$, with a final extension of $72{ }^{\circ} \mathrm{C}$ for $10 \mathrm{~min}$. Each PCR assay included a negative control (distilled water instead of flea DNA template) and a positive control (with DNA from $R$. raoultii obtained from wetlands of Ebinur Lake in XUAR) [17]. Purification and sequencing of the positive PCR products were as described above. A phylogenetic tree was constructed using the maximum-likelihood and neighbor-joining algorithms implemented in MEGA 6 software [18].

\section{Results}

The collected fleas were identified primarily as $V$. alakurt by morphological identification. Their foreheads were smooth and curved without outgrowths. The head of the intromittent organ of the male fleas looks like winter gloves (with the back four fingers held together) (Fig. 1a, b). The head of the spermathecae is ellipsoid, and the tail part is thin and long, with a sausage-like shape (Fig. 1c, d). Data on the four nucleotide sequences (18S rDNA, 28S rDNA, COII and EF-1a) from the six fleas indicated that the fleas obtained from the sheep had similarity values of 99.22, 98.28, 87.62 and $91.29 \%$, respectively, with Chaetopsylla (Vermipsyllidae) (no V. 

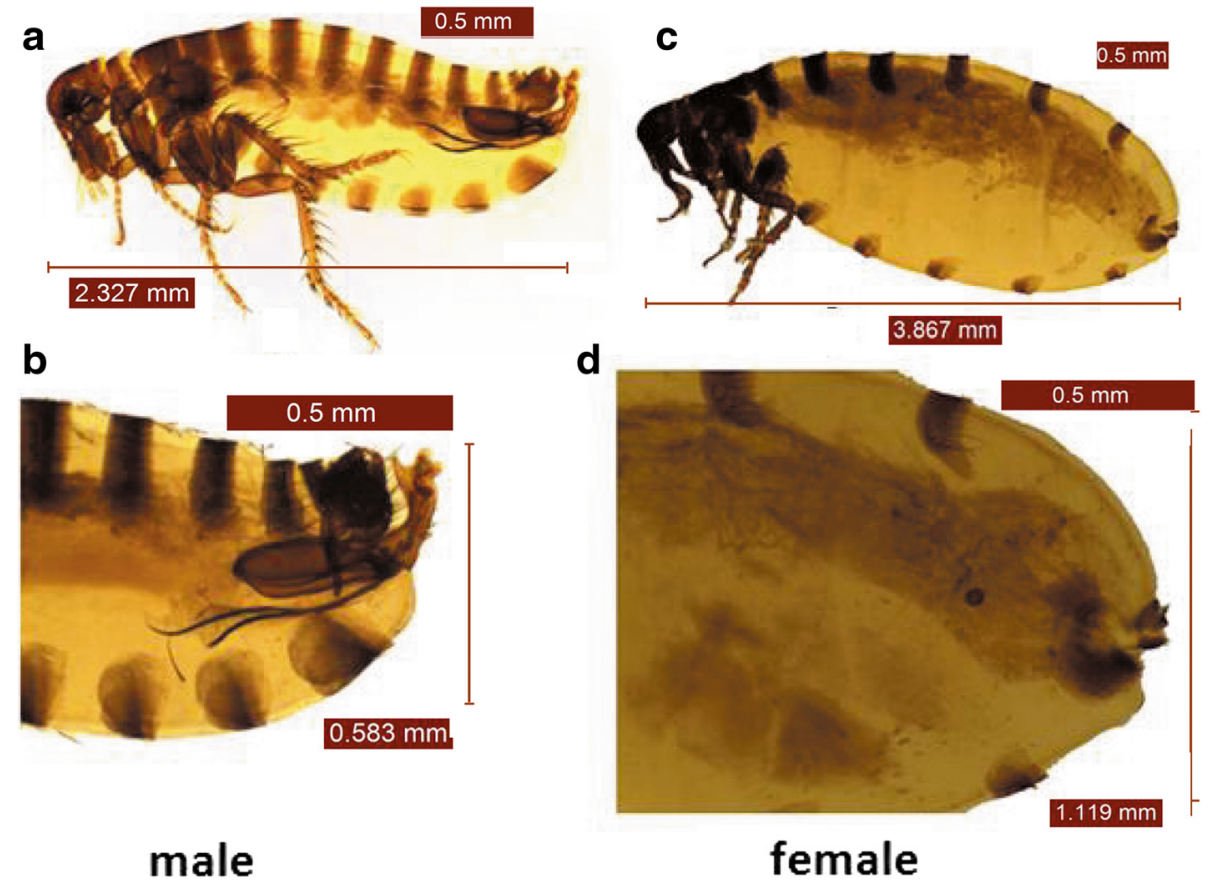

Fig. 1 Photomicrographs of Vermipsylla alakurt. a Male, total view. b Male, posterior part of the abdomen. c Female, total view. d Female, posterior part of the abdomen. The specimens are visualised using a stereomicroscope LEICA EZ4HD equipped with a digital camera

alakurt sequence was available in the GenBank database). Four nucleotide sequences from our study have been deposited in the GenBank database (18S rDNA: KR297206; $28 S$ rDNA: KR297207; COII: KT193612; and EF-1a: KT193613).

Among the 53 flea samples, nine were found to be positive for six rickettsial genetic markers $(17-k D a$, ompA, gltA, rrs, sca1 and $о m p B)$. The positive samples were from two sheep flocks. BLAST analysis showed that three of the genetic markers exhibited 99.83 to $100 \%$ similarity with the corresponding sequences of Candidatus $R$. barbariae. The genes $g l t A, \operatorname{omp} B$ and scal were exceptions. This was attributed to: (i) the length of the gltA sequence from our study was $1080 \mathrm{bp}$, longer than the available sequences for Candidatus $R$. barbariae in GenBank; (ii) the partial region of $о m p B$ used in this study (accession no. KT284717) was different from the fragment of the Candidatus $R$. barbariae available in GenBank (accession no. GU353186); (iii) there is no scal reference sequence available from Candidatus $R$. barbariae. To further identify the rickettsial agent in $V$. alakurt, another region of ompB (526 bp, accession no. KU645285) and gene D, encoding PS120-protein (920 bp, accession no. KU645286), were studied. The BLAST analysis of these sequences showed that they had, respectively, $100 \%$ similarity with Candidatus $R$. barbariae in the loci $\operatorname{omp} B$ and gene $D$. The detailed sequence information from our study is deposited in the GenBank database (KT284715-KT284718 and KU645283-KU645286). The phylogenetic tree produced from the maximum likelihood and neighbor-joining analyses of the sequence data for five genes (17-kDaompA-rrs-geneD-ompB) revealed that the rickettsial agent in $V$. alakurt clustered with Candidatus $R$. barbariae (Fig. 2).

\section{Discussion}

Candidatus $R$. barbariae, first identified in Rhipicephalus bursa ticks from Portugal in 2006 and named Rickettsia sp. PoTiRb169 [19], was confirmed and characterised by five genetic markers ( $g l t A, o m p A, o m p B, s c a 4$ and $r r s)$ in $R h$. turanicus from Italy in 2008 [20]. Subsequently, the Candidatus $R$. barbariae genotype was respectively detected in Rh. turanicus from Cyprus in 2011 and in $R h$. turanicus and $R h$. sanguineus from Israel in 2014 $[21,22]$. To confirm that the southern region of XUAR might be a natural focus for Candidatus $R$. barbariae, a total of $117 R h$. turanicus were collected from sheep during 2013-2014 in six counties around the Taklimakan Desert with the help of Associate Prof. Shi-Wei Wang (College of Animal Science \& Technology, Tarim University). Of these, 36 samples (30.76\%) from the six counties were positive for Candidatus $R$. barbariae by seven rickettsial genetic markers (17-kDa, gltA, rrs, ompA, sca1, gene $D$, and ompB). Additionally, we concluded that Candidatus $R$. barbariae may have cocirculated with $R$. massiliae and $R$. conorii, vectored as 


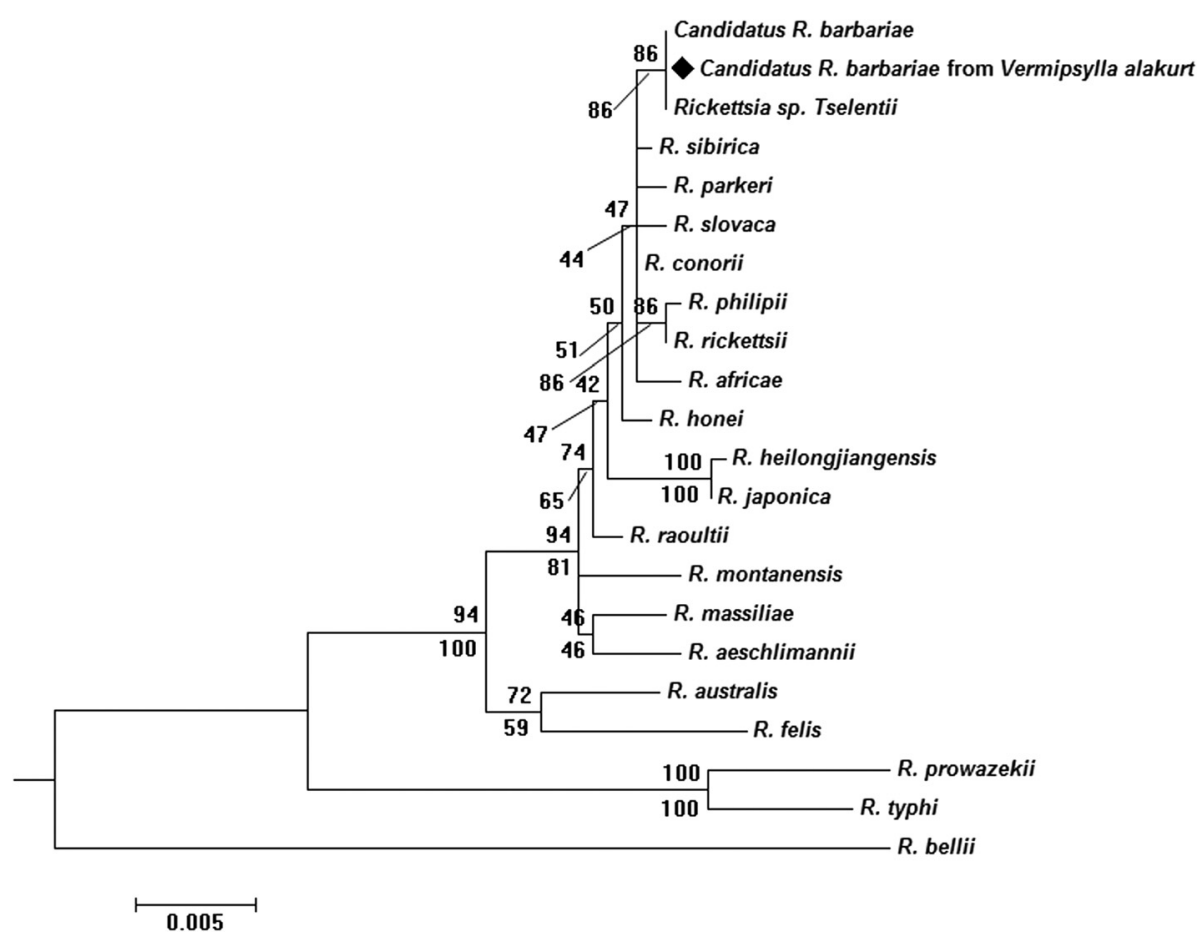

Fig. 2 Maximum-likelihood (ML; 1000 bootstrap replicates) and neighbour-joining (NJ; 500 bootstrap replicates) phylogenetic tree of the 17-kDaompA-rrs-geneD-ompB constructed with MEGA6, using the sequences of Candidatus R. barbariae from Vermipsylla alakurt ( $\bullet$ in this study and sequences from Rickettsia species retrieved from the GenBank database. The sequences for $R$. bellii were used as an outgroup. The scale bar represents the inferred substitutions per nucleotide site. The relative support for clades in the tree produced from the ML and NJ analyses are indicated above and below the branches, respectively

Rh. turanicus, near the Taklimakan Desert before 2013. These findings will be reported in a separate paper.

Candidatus $R$. barbariae, an emerging member of the rickettsial spotted fever group (SFG) [21], has not been reported previously in fleas. Although the vast majority of the SFG rickettsiae are transmitted by ticks, there are exceptions. Rickettsia africae, a member of the SFG ordinarily transmitted by ticks, was detected in Ceratophyllus garei fleas from passerine birds that had migrated from Africa [23]. Herein, we report the presence of Candidatus $R$. barbariae in $V$. alakurt fleas from sheep in an alpine pastoral area in the north-west of China. This has extended our knowledge of the potential vector spectrum of Candidatus $R$. barbariae.

To date, seven validated SFG Rickettsia spp. have been detected in China: $R$. heilongjiangii, $R$. sibirica, $R$. raoultii, $R$. slovaca, $R$. felis, $R$. aeschlimannii and $R$. massiliae $[17,24]$. Rickettsia felis was first confirmed in ticks (Rh. sanguineus), mosquitoes (Anopheles sinensis and Culex pipiens pallens), lice (Linognathus setosus) and fleas (Ctenocephalides felis) in China [25]. Here, Candidatus $R$. barbariae, as the eighth validated Rickettsia species, was found in China. To the best of our knowledge, this finding extends the area of occurrence for Candidatus $R$. barbariae, and is the second report in Asia.
Our findings suggest that the $V$. alakurt parasitising sheep may serve as a carrier for Candidatus $R$. barbariae. In the future, Candidatus $R$. barbariae should be genotypically explored by using genomic sequences or other genetic markers. Addtionally, this rickettisial agent should be further investigated in a wider spectrum in arthropods.

\section{Conclusions}

This is the first report of the presence of Candidatus $R$. barbariae in $V$. alakurt fleas rather than ticks, and of the occurrence of Candidatus $R$. barbariae in China. These findings extend our knowledge of the geographical distribution and reservior hosts for Candidatus $R$. barbariae.

\section{Abbreviations}

SFG, spotted fever group; SU, Shihezi University; XAAS, Xinjiang Academy of Animal Sciences; XUAR, Xinjiang Uygur Autonomous Region

\section{Acknowledgements}

We would like to thank Dr Ke Zhang for the sequences submitted to the GenBank, Pro. Renfu Shao and Xinquan Zhu revised the manuscript.

\section{Funding}

This research was supported in part by grants from the National Natural Science Foundation of China (Granted No. 81560338 and U1503283). 


\section{Availability of data and material}

The datasets supporting the conclusions of this article are available in the GenBank (National Center for Biotechnology Information) [unique persistent identifier and hyperlink to datasets in http://www.ncbi.nlm.nih.gov/genbank/].

\section{Authors' contributions}

YZW conceived and designed the study and critically revised the manuscript. XPY, ZQL, CFC and YZW performed flea collection. SSZ, HYL and XPY performed the laboratory work. All authors read and approved the final manuscript.

\section{Competing interests}

The authors declare that they have no competing interests.

\section{Consent for publication}

Not applicable.

\section{Ethics approval and consent to participate}

This study was approved by the Animal Ethics Committee of Shihezi University (Approval No. AECSU2013-17)

\section{Author details}

'School of Medicine, Shihezi University, Shihezi, Xinjiang Uygur Autonomous Region 832000, China. ${ }^{2}$ Alashankou Entry-Exit Inspection and Quarantine Bureau, Alashankou 833418, China. ${ }^{3}$ College of Animal Science and Technology, Shihezi University, Shihezi 832000, China.

\section{Received: 24 February 2016 Accepted: 31 May 2016}

\section{Published online: 07 June 2016}

\section{References}

1. Bitam I, Dittmar K, Parola P, Whiting MF, Raoult D. Fleas and flea-borne diseases. Int J Infect Dis. 2010;14(8):e667-76.

2. Whiting MF, Whiting AS, Hastriter MW, Dittmar K. A molecular phylogeny of fleas (Insecta: Siphonaptera): origins and host associations. Cladistics. 2008:24:677-707

3. Lewis RE, Lewis JH. Siphonaptera of North America north of Mexico: Vermipsyllidae and Rhopalopsyllidae. J Med Entomol. 1994;31(1):82-98.

4. Lewis RE. Notes on the geographical distribution and host preferences in the order Siphonaptera. 2. Rhopalopsyllidae, Malacopsyllidae and Vermipsyllidae. J Med Entomol. 1973;10(3):255-60.

5. Lewis RE. A new species of Chaetopsylla Kohaut, 1903, infesting pikas in Nepal (Siphonaptera: Vermipsyllidae). J Parasitol. 1971;57(6):1344-8.

6. Liu ZY, Wu HY, Wu FL. On two new species of Vermipsylla from west China and a revision of the characters of the genus (Siphonaptera: Vermipsyllidae). Acta Zool Sinica. 1965;17(4):406-13.

7. ZipcodeZoo. Vermipsylla alakurt. http://zipcodezoo.com/index.php/ Vermipsylla. Accessed 3 Jan 2011.

8. Zhao CG, Zhang JS, Meng QL, Qiao J, Shi GJ, et al. Morphological identification of Vermipsyllidae parasiting sheep collected from Tacheng region in Xinjiang. Chin J Prevent Vet Med. 2012;34(7):539-42.

9. Yao HR, Wang CJ. Investigation on Vermipsyllidae infesting sheep in Hualong County, Qinghai Province. Chin J Vet Med. 2008;44(5):42-3.

10. Wang GL, Nuer B, Si M, Zhang JC, Xu XJ, Aimaier Y, et al. Outbreak of Vermipsyllidae infesting livestock in Minfeng County, Xinjiang Uygur Autonomous Region. Chin J Vet Parasito. 2000;8(1):24-5.

11. Vaughan JA, Thomas RE, Silver GM, Wisnewski N, Azad AF. Quantitation of cat immunoglobulins in the hemolymph of cat fleas (Siphonaptera: Pulicidae) after feeding on blood. J Med Entomol. 1998;35(4):404-9.

12. Eisen RJ, Gage KL. Transmission of flea-borne zoonotic agents. Annu Rev Entomol. 2012:57:61-82

13. McElroy KM, Blagburn BL, Breitschwerdt EB, Mead PS, McQuiston JH. Fleaassociated zoonotic diseases of cats in the USA: bartonellosis, flea-borne rickettsioses, and plague. Trends Parasitol. 2010;26(4):197-204.

14. Leulmi H, Socolovschi C, Laudisoit A, Houemenou G, Davoust B, et al. Detection of Rickettsia felis, Rickettsia typhi, Bartonella Species and Yersinia pestis in Fleas (Siphonaptera) from Africa. PLoS Negl Trop Dis. 2014;8(10):e3152.

15. Wang $Y$, Wang $G$, Cong $P Q, Y u$ YW. Study on lifecycle of Vermipsylla alakurt. Shandong J Anim sci vet Med. 2013;34(12):74-5.
16. Anstead CA, Chilton NB. A novel Rickettsia species detected in vole ticks (Ixodes angustus) from Western Canada. Appl Environ Microbiol. 2013:79(24):7583-9.

17. Guo LP, Mu LM, Xu J, Jiang SH, Wang AD, et al. Rickettsia raoultii in Haemaphysalis erinacei from marbled polecats, China-Kazakhstan border. Parasit Vectors. 2015;8:461.

18. Tamura K, Stecher G, Peterson D, Filipski A, Kumar S. MEGA6: molecular evolutionary genetics analysis version 6.0. Mol Biol Evol. 2013;30(12):2725-9.

19. de Sousa R, Barata C, Vitorino L, Santos-Silva M, Carrapato C, Torgal J, et al. Rickettsia sibirica isolation from a patient and detection in ticks, Portugal. Emerg Infect Dis. 2006;12(7):1103-8.

20. Mura A, Masala G, Tola S, Satta G, Fois F, Piras P, et al. First direct detection of rickettsial pathogens and a new rickettsia, 'Candidatus Rickettsia barbariae', in ticks from Sardinia, Italy. Clin Microbiol Infect. 2008;14(11):1028-33.

21. Chochlakis D, loannou I, Sandalakis V, Dimitriou T, Kassinis N, et al. Spotted fever group Rickettsiae in ticks in Cyprus. Microb Ecol. 2012;63(2):314-23.

22. Waner T, Keysary A, Eremeeva ME, Din AB, Mumcuoglu KY, et al. Rickettsia africae and Candidatus Rickettsia barbariae in ticks in Israel. Am J Trop Med Hyg. 2014;90(5):920-2

23. Sekeyová Z, Mediannikov O, Roux V, Subramanian G, Spitalská E, et al. Identification of Rickettsia africae and Wolbachia sp. in Ceratophyllus garei fleas from passerine birds migrated from Africa. Vector Borne Zoonotic Dis. 2012:12(7):539-43.

24. Wei QQ, Guo LP, Wang AD, Mu LM, Zhang K, et al. The first detection of Rickettsia aeschlimannii and Rickettsia massiliae in Rhipicephalus turanicus ticks, in northwest China. Parasit Vectors. 2015;8(1):631.

25. Zhang J, Lu G, Kelly P, Zhang Z, Wei L, et al. First report of Rickettsia felis in China. BMC Infect Dis. 2014;14:682.

26. Whiting MF. Mecoptera is paraphyletic: multiple genes and phylogeny of Mecoptera and Siphonaptera. Zool Scr. 2002;31(1):93-104.

27. Maekawa K, Kitade O, Matsumoto T. Molecular phylogeny of orthopteroid insects based on the mitochondrial cytochrome oxidase II gene. Zoologicalence. 1999;16:175-84.

\section{Submit your next manuscript to BioMed Central and we will help you at every step:}

- We accept pre-submission inquiries

- Our selector tool helps you to find the most relevant journal

- We provide round the clock customer support

- Convenient online submission

- Thorough peer review

- Inclusion in PubMed and all major indexing services

- Maximum visibility for your research

Submit your manuscript at www.biomedcentral.com/submit 